\title{
O FUTURO ANTERIOR: CONTINUIDADES E RUPTURAS NOS MOVIMENTOS ESTUDANTIS DO BRASIL ${ }^{1}$
}

\section{Breno Bringel}

Durante o ano de 2008, multiplicaram-se, em todo o mundo, as reflexôes sobre as lutas estudantis motivadas pelo $40^{\circ}$ aniversário do Maio de I968. No caso brasileiro, a questão mais paradigmática não foi tanto a discussão das lutas da década de I960, mas sua "atualização" no contexto nacional, tendo como base possíveis rupturas que as lutas recentes dos estudantes universitários brasileiros, com vários protestos e ocupaçóes entre 2007 e 2008, podem provocar no cenário dos movimentos estudantis no Brasil. Uma das hipóteses centrais propostas neste artigo é que esses movimentos se manifestam de acordo com dinâmicas cíclicas, e pela retroalimentação com outros movimentos sociais. Para observar essa dinâmica de continuidade e ruptura propóem-se alguns elementos para uma abordagem teórico-metodológica que interprete os movimentos estudantis como um movimento social sui generis. Realizase também uma análise cíclica das açóes coletivas estudantis no Brasil e se avaliam, em perspectiva histórica e comparada com as dinâmicas de outros movimentos sociais, as principais características das lutas dos movimentos estudantis contemporâneos no País.

Palavras-chave: Movimentos sociais. Estudantes. Ocupações. Protestos. Universidade.
Pesquisador do Departamento de Ciência Política III e do Grupo de Estudos Contemporâneos da América Latina - Universidad Complutense de Madri.

Madri [Espanha]

brenobringel@hotmail.com

I Algumas das ideias apresentadas neste artigo foram discutidas em dois congressos internacionais: o XV Congresso Internacional de Latinoamericanistas da Europa (Leiden, Holanda, agosto de 2008) e a Conferência Internacional "Globalização, Educação e Cidadania” (João Pessoa, Brasil, fevereiro de 2008). 


\section{Introdução. Para não esperar dez anos mais...}

O ano de 2008 esteve marcado, tanto para o meio acadêmico quanto para os militantes de praticamente todo o mundo, por várias reflexốes e debates sobre os significados, sentidos e atualidade do Maio de 1968. De acordo com Ana Maria Sáenz (2008), pesquisadora do seminário sobre movimentos estudantis do Instituto de Investigaciones Bibliográficas da Universidade Nacional do México (UNAM), em uma apresentaçáo recente sobre a produçáo bibliográfica do 1968 estudantil mexicano, a 40 anos de sua irrupçáo, somente em 1998 , no $30^{\circ}$ aniversário, foi lançada uma produção similar ou mesmo superior à que vimos chegar às bibliotecas e livrarias em 2008. $\mathrm{O}_{40^{\circ}}$ aniversário serviu, assim, de motivo simbólico para reabrir uma discussão sempre inacabada e que náo pode esperar até o ano 2018 , quando se cumpriráo 50 anos de I968, para ser retomada.

A reflexão sugerida, por meio deste ensaio é que no caso brasileiro, apesar da ênfase dada às lutas do Maio de 1968, a questão mais paradigmática não foi tanto a discussão dessas lutas per se, mas sua "atualização" no contexto nacional, com base em possíveis rupturas que as lutas recentes dos estudantes universitários brasileiros, por meio de muitos protestos, ocupaçôes e outras açôes coletivas desenvolvidas entre 2007 e 2008, podem provocar no cenário desse movimento no Brasil. Uma das hipóteses centrais propostas é que se manifestam de acordo a dinâmicas cíclicas e da retroalimentação com outros movimentos sociais. Com esse pano de fundo, o artigo está divido em quatro partes: na primeira, propóem-se alguns elementos para uma abordagem teórico-metodológica que interprete os movimentos estudantis como um movimento social sui generis; na segunda, aprofunda-se no estudo dos movimentos estudantis tendo como base as teorias dos movimentos sociais; já na terceira, realizase uma breve análise cíclica das açôes coletivas estudantis no Brasil, para 
centrar-se na quarta e última parte nas lutas recentes dos movimentos estudantis do País.

Neste estudo, serão expostos somente resultados parciais de uma pesquisa mais ampla em andamento que utiliza uma metodologia mista, que combina a observação participante, resultado de intermináveis assembleias na Universidade Estadual de Campinas (Unicamp) e noites maldormidas na reitoria da Universidade de São Paulo (USP), o recurso a fontes primárias (obtidas em panfletos, blogs confeccionados pelo movimento estudantil em cada reitoria ocupada e material audiovisual produzido nas ocupações) e algumas entrevistas abertas, com participantes da ocupação da reitoria da Universidade Federal da Bahia (UFBA) e de mobilizaçóes da Universidade Federal de Sergipe (UFS). A observação participante, como ferramenta de pesquisa por meio da qual o pesquisador verifica e, em algumas ocasióes, participa das açóes, serviu de importante recurso metodológico para aprofundar as vivências e subjetividades dos estudantes presentes nas mobilizaçóes em questão. Por outro lado, as entrevistas abertas foram realizadas de forma complementar não só para identificar questôes fundamentais diagnosticadas na observação participante, mas também para cobrir zonas geográficas a que o pesquisador-militante não pôde chegar. Finalmente, outro aspecto a destacar é o acesso a fontes primárias confeccionadas pelos próprios estudantes por meio de internet, algo que será objeto específico de análise, em razão de seu caráter inovador nas mobilizações estudantis no País.

Nesse sentido, ao tratar-se de resultados parciais, as propostas não têm a pretensão (nem poderia) de abarcar a totalidade das questóes relacionadas ao recente fluxo dos movimentos estudantis brasileiros, mas, sim, procura analisar o movimento estudantil como uma totalidade, como ator/sujeito complexo, heterogêneo e contraditório, pretendendo, ademais, interpretá-lo de acordo com as teorias dos movimentos sociais. 


\section{O movimento estudantil: um movimento social suigeneris}

Os movimentos estudantis, da mesma forma que os de mulheres, camponeses, indígenas, urbanos e outros, são movimentos sociais. Essa afirmação que poderia parecer óbvia tem profundas implicaçóes teóricas e, apesar de algumas exceçóes destacadas adiante, dista muito do trato que os movimentos estudantis receberam (e recebem), na maioria das análises, sobre os movimentos sociais. Sua aceitação dependerá fundamentalmente do conceito de movimentos sociais utilizado. No caso das lutas estudantis no Brasil, o termo "movimento" tem sido extensamente utilizado e escassamente debatido, em razão de seu uso num sentido laxo e ampliado, empregado há várias décadas, de forma quase imediata, quando um grupo de estudantes se mobiliza. Isso tem três implicações perigosas que levam à confusão entre:

a) Ação coletiva versus movimento social/estudantil: com frequência, vários intérpretes (sejam acadêmicos, políticos ou meios de comunicação) veem em uma ação o "movimento estudantil”, quando, na realidade, o que existe é somente uma ação coletiva (a exemplo de um protesto isolado no refeitório de uma faculdade). Essas açóes podem ou não ser resultado da atuação de um "movimento estudantil”, mas, se isoladas, são simplesmente uma ação coletiva;

b) Movimento estudantil versus organização estudantil: este equívoco normalmente advém da atribuição ao "movimento estudantil" de uma ação coletiva específica convocada por uma organização ou entidade estudantil institucionalizada, algo bem diferente e que se tornou habitual no Brasil durante a década de I990. Somente se tratará de um movimento estudantil se a organização não estiver institucionalizada; 
c) Movimento estudantil, em singular, versus movimentos estudantis, em plural: o leque de movimentos camponeses, urbanos e feministas é muito amplo. No cenário brasileiro atual, poder-se-ia destacar, entre os primeiros, o Movimento dos Trabalhadores Rurais Sem-Terra (MST), o Movimento de Pequenos Agricultores (MPA) e o Movimento de Mulheres Camponesas (MMC). Isso significa que existem vários movimentos sociais de camponeses, embora o MST seja a principal força. A mesma regra é válida para os movimentos urbanos, feministas, estudantis e outros. No caso dos movimentos estudantis, quando se fala de "movimento" em singular não se deve ocultar a existência de diferentes movimentos estudantis, em plural, e as tensões que há entre eles.

Com essas observações iniciais, nota-se que os movimentos estudantis são de difícil caracterização e definição. Com base em uma densa análise histórica comparada que remonta às origens e a rasgos básicos dos movimentos estudantis no século XIX e sua evolução no século XX em várias partes do mundo, Feuer (I969), em obra clássica sobre o tema, parte de uma perspectiva marxista para sugerir que, enquanto a maioria das lutas sociais está permeada por um conflito de classe, às lutas dos estudantes subjaz outro tipo de conflito, o geracional. Compara assim o status esporádico e transitório do estudante na universidade com a trajetória mais estável ou contínua dos operários nas fábricas (algo menos nítido na atualidade com a incessante flexibilidade e precariedade dos mercados laborais), introduzindo categorias de análises distintas para compreender ambos os casos. Desse modo, Feuer define o movimento estudantil como uma coalizão de estudantes inspirada em propósitos que procuram traduzir-se numa ideologia política, e impulsionada por uma rebelião emocional em que estão latentes a desilusão e a rejeição dos valores da velha geração. Talvez um dos aspectos mais interessantes do inovador estudo realizado pelo autor seja sua consideração sobre o caráter "particular" das lutas estudantis na comparação com outras lutas sociais como as operárias. 
Este diagnóstico, se atualizado considerando a importância dos diferentes paradigmas e teorias dos movimentos sociais que emergiram com sua institucionalização acadêmica como objeto de estudo, a partir da década de I960, é a base para considerar o movimento estudantil um movimento social sui generis, assinalando tanto aqueles elementos que o unem aos demais movimentos sociais quanto seus rasgos característicos ou específicos. Nesse sentido, em primeiro lugar, as lutas, reivindicaçôes e açóes coletivas dos estudantes, somente se traduzem em um movimento estudantil quando articulam uma série de elementos mínimos, que também estão presentes nos demais movimentos sociais: definição de reivindicaçóes, demandas e objetivos coletivos; exposição dessa problemática a interlocutores políticos por meio de diferentes estratégias e repertórios de ações coletivas; mínima organização com certo grau de continuidade no tempo; caráter não institucional; trabalho comum que leva à construçáo de uma identidade coletiva, mesmo que incipiente. Em segundo lugar, como "mínimo denominador comum”, torna-se necessário assinalar alguns rasgos específicos dos movimentos estudantis:

- A maioria de suas lutas tem um objetivo específico de curto prazo, pois se trata de uma força social conjuntural. Contudo, isso não impede que existam mobilizaçóes que permaneçam em um horizonte de médio ou longo prazo, dependendo da conjuntura e das forças sociais e políticas existentes. Os movimentos estudantis universitários estão muito influenciados pelo ritmo do ano letivo acadêmico: férias e feriados acabam atuando como elementos desmobilizadores, que rompem com a sequência de ações coletivas iniciadas. Além disso, outro elemento crucial (e prejudicial para a continuidade dos movimentos estudantis) é a questão do "relevo geracional", que muitas vezes impede que os movimentos estudantis disponham de um "capital militante" acumulado de outras lutas, visto que a maioria dos participantes de mobilizaçóes 
anteriores acaba se desvinculando da universidade e/ou, pelo menos, da militância estudantil;

- Sua organização é pendular e variável. Não responde a uma forma de organizaçáo concreta, contando com diferentes graus de estruturas e organicidade. As assembleias conformam o coração da atividade política dos movimentos estudantis, porém pode haver múltiplas formas de canalizar o trabalho realizado nelas para âmbitos mais amplos, assim como outros formatos mais formais de organização;

- Sua composição social está constituída principalmente por setores das classes médias, algo contemplado nos movimentos estudantis que estudamos tanto na Europa quanto na América Latina, e que os diferencia dos movimentos "populares", conformados principalmente por um extrato mais pobre da população;

- Possuem, com frequência, o que poderia ser identificado como uma "identidade secundária" ou de "baixa intensidade", em razão de uma habitual convergência de perfis e identidades militantes quando o estudante também milita em outro movimento social (seja este negro, feminista etc.) ou em alguma força política (normalmente partidos políticos), priorizando alguns deles. Ademais, pelo caráter de curto prazo de muitas das lutas, torna-se mais complexa a construção de uma identidade coletiva profunda;

- Converge um amplo espectro ideológico na composição dos movimentos estudantis, que normalmente varia desde a socialdemocracia até a esquerda mais radical, incluindo um amplo leque de "sensibilidades" de esquerda. No entanto, da mesma forma que nem todo movimento social é de esquerda, nem todos os movimentos estudantis são de esquerda, nem todas as lutas estudantis têm um caráter transformador (ou de radicalismo absoluto como chegou a ser mistificado de forma equivocada), adquirindo, muitas vezes, esse caráter quando a esquerda está no poder num marco mais amplo, como é o caso atual de muitas 
lutas estudantis de direita na Venezuela, que conseguem mobilizar um numeroso contingente de estudantes;

- As demandas podem ter um caráter interno (reivindicações endógenas como residência universitária, restaurantes, discussóes sobre o uso do espaço universitário etc.) ou externo (questionamentos que vão além das demandas de grêmio e que procuram incidir em discussóes de maior alcance político, como a qualidade do ensino público ou o papel que deveriam desempenhar as universidades nas sociedades contemporâneas). Ainda que não se trate de uma divisão rígida entre ambas as dimensóes, a hegemonia das demandas de caráter interno está ligada a um menor papel dos movimentos estudantis como movimentos antissistêmicos. Pelo contrário, ao articular as reivindicaçóes internas com questóes externas, de maior alcance, como as políticas educativas de um governo ou temas da política local, nacional ou global, essas lutas adquirem maior grau de protagonismo em nível societário. Um bom exemplo recente é o dos estudantes secundaristas no Chile que, ao questionarem o caráter neoliberal das políticas educativas de Bachelet, puseram em xeque o próprio governo do país.

\section{Continuidades e rupturas}

Essas singularidades também levam autores como Ibarra e Bergantiños (2008, p. 22-26) a considerar o movimento estudantil como "[...] um movimento social peculiar." Para esses autores, ainda que os movimentos estudantis não contenham todas as características "clássicas" dos movimentos sociais (entre as quais, certa estabilidade e uma identidade coletiva densa), apresentam rasgos suficientes (organização, meios de ação, estratégias etc.) que lhes outorgam essa dimensão. Outros autores como Aranda (2000) também buscaram interpretar os movimentos estudantis, neste caso os mexicanos, de acordo 
com as teorias dos movimentos sociais, a partir de um diálogo com o enfoque nos "novos movimentos sociais", enfatizando sua composição heterogênea, sua organização baseada em uma liderança múltipla e uma atitude predominantemente antiestatal (ARANDA, 2000, p. 230). Não deixa de ser uma maneira de retomar um debate já "clássico" entre os estudiosos dos movimentos sociais, lembrando que as mobilizaçóes estudantis dos anos I960, do México à França, do Brasil aos Estados Unidos, contribuíram, sobremaneira, para revitalizar os estudos sobre os movimentos sociais, principalmente nos Estados Unidos e na Europa, servindo de base para os movimentos ambientalistas, de mulheres, homossexuais ou pela paz, para a formulação dessa complexa articulação teórico-conceitual que se chamou de "novos movimentos sociais"2. Também num diálogo com a corrente dos "novos movimentos sociais", provavelmente tenha sido Laraña (1994) quem melhor apontara para duas tensôes centrais no debate sobre os movimentos estudantis: a continuidade/descontinuidade e a unidade/divergência. A exploração dessas questôes permitiu ao autor ensaiar respostas para explicar, por exemplo, o porquê da descontinuidade do movimento estudantil em um lugar, como o campus de Berkeley, que, no fim dos anos 1960, havia sido o centro do ativismo estudantil nos Estados Unidos; ou, de forma inversa, o porquê do surgimento de um movimento estudantil como o de Madri, durante os anos I986 e I987, que parecia emergir "do nada”. Essa questão remete não somente às origens de um movimento social, mas também a uma problemática amplamente tratada entre os teóricos dos "novos movimentos sociais": a tendência a interpretar as fases visíveis desses movimentos, aquelas de alta agitação política e social, dando prioridade ao seu significado político mais amplo, em detrimento do cultural.

Eis uma advertência importante para o estudo dos movimentos estudantis brasileiros. Por um lado, ao enfatizar principalmente a década de 1960, período marcado por intensas mobilizaçóes estudantis e protestos, criou-se uma representação "mitológica” da geração de 1960, que, para Martins Filho (1987), pode ser localizada na própria autoimagem elaborada pela liderança
2 Para uma revisão dessas correntes teóricas, vide Gohn (2006) e Neuveu (1996). 
3 É o que acontece com as transições políticas à democracia em vários países da América Latina, do Sul e Leste da Europa. Ao receberem atençáo especial dos estudiosos dos movimentos sociais, que analisaram como as práticas e discursos desses movimentos contribuíram para a passagem de regimes autoritários a democracias emergentes, acabaram construindo uma barreira para uma análise mais contínua e complexa das pautas democratizantes dos movimentos sociais, pois as transições passaram a atuar como um "momento histórico" referencial. Vide Bringel e Echart (2008).

4 Um excelente livro que reconstrói essas mobilizaçóes estudantis na Espanha e na França com documentos, depoimentos e reflexóes é a compilaçấo do Colectivo Maldeojo (200I). universitária, plasmada hoje na historiografia oficial da União Nacional de Estudantes (UNE). A ausência de mobilizaçôes significativas de caráter nacional e de uma política transformadora no movimento estudantil brasileiro no contexto pós-ditatorial também contribui para esse recurso constante de recorrer às lutas estudantis contra a ditadura como "momento histórico privilegiado" . Desse modo, apesar de uma rica produção dedicada à juventude, à questáo da sociologia da educação e aos rumos da universidade no Brasil, em que se destacam alguns trabalhos de grandes nomes do pensamento social brasileiro, tais como Octavio Ianni (I968), Darcy Ribeiro (I969), Ruy Mauro Marini (I970) e Florestan Fernandes (I979), a atenção dada aos movimentos estudantis propriamente ditos centrou-se na análise do que antes se identificava como sua "parte visível". Por outro lado, o despertar recente dos movimentos estudantis brasileiros, que rompem com vários anos de apatia de mobilização, suscita o interesse sobre as causas de proliferação das lutas estudantis universitárias durante os anos 2007 e 2008, de forma similar à de Laraña (I994), que, apesar das diferenças espaço-temporais, se perguntava sobre o aparecimento de um movimento estudantil renovado em Madri, em I986, depois de décadas de apatia.

As convergências entre o renascimento da mobilização estudantil brasileira em 2007 e 2008 e as de Madri e de Paris, duas décadas antes, não se dão somente no plano da irrupção de um protesto renovado depois de muitos anos de inércia, mas também em razão do "efeito irradiação" (que provoca um incentivo à extensão da luta a outros pontos das geografias nacionais. Paris, Madri e São Paulo serviram de catalisadores nestes casos), a forma assembleária de organização e deliberação, a crítica aos canais institucionais da política, os ataques recebidos dos meios de comunicação hegemônicos, a incapacidade dos governantes de interpretar os acontecimentos e leitmotiv das açóes estudantis ${ }^{4}$.

Além disso, essa comparação permite outro ponto de contato: a presença de elementos passados nas mobilizaçóes presentes. Conforme também se 
pode observar nas mobilizaçóes estudantis atuais existentes tanto na Espanha quanto na França contra o denominado "Plano Bolonha", plano de reestruturação do Espaço Europeu de Educação Superior (EEES), as realizadas 1986 e 1987 já anunciavam uma silhueta ou antecipação de futuro. Nesse sentido, poder-se-ia dizer que os movimentos estudantis brasileiros vivem um período de transição, em que coexistem elementos do passado com tendências que apontam para seu futuro. Isso conforma seu "futuro anterior", que não significa somente uma construção resultante da conjunção dos verbos "mobilizar", "protestar" e "construir" no futuro indicativo com o particípio passado, mas também em sentido derridiano, um "paradoxo da antecipação" (DERRIDA, 1967), que em um mesmo movimento amplia e fecha a abertura do futuro, resgatando a memória. É desse resgate da atualidade que parecem renascer as novas mobilizaçóes estudantis.

\section{Da ditadura à institucionalização da ação coletiva: o movimento estudantil brasileiro no espelho histórico}

Uma questão central para abordar essa problemática é pensar não só a importância do aspecto macro da conjuntura política, econômica e social (por exemplo, as lutas contra a ditadura num cenário mais polarizado na década de I960 ou num cenário de maior complexidade e imbricaçôes a partir da década de 1990), mas também contextualizar o significado cultural e a socialização política desses estudantes universitários num entorno renovado de militância a partir de início do século XXI. Por meio da observação participante e das entrevistas realizadas nas últimas mobilizações estudantis de 2007 e 2008, observou-se uma preocupação com o debate sobre a autonomia, em um contexto em que muitos dos estudantes já não são membros de sindicatos ou de partidos políticos, alinhando-se mais ao que poderia denominar-se de "geração Fórum Social Mundial". Observou-se, assim, que a irrupção desses 
protestos esteve marcada por uma aproximação com as formas de organização e atuação do movimento antiglobalização, o que exige uma maneira renovada de interpretar essas lutas estudantis.

Para observar essas continuidades e rupturas dos movimentos estudantis brasileiros e anunciar as mudanças e possíveis rupturas que emergem com as recentes mobilizaçóes, nada melhor que uma análise cíclica da ação coletiva. Trata-se de uma ferramenta interpretativa introduzida nos estudos sobre os movimentos sociais nos primeiros trabalhos de Tilly (I978 e 1984) e que alcançaria um desenvolvimento mais notável em trabalhos de Tarrow (I99I e 1998). Nesses trabalhos, Tarrow aponta que uma das vantagens de analisar ciclos inteiros de protesto é estabelecer diferentes fases de mobilização social, entender as açóes coletivas vis-à-vis ao entorno político, contribuindo para prever os "sucessos" ou "derrotas" dos movimentos (TARROW, I99I, p. 4950). A utilidade desse enfoque para o estudo dos movimentos estudantis no Brasil é permitir a composição de diferentes ciclos de mobilização estudantil no País, que possibilitam uma abordagem histórica contínua das lutas dos estudantes, evitando as mistificaçóes de determinados períodos históricos, e contribuem para identificar os períodos de mobilização e desmobilização, ainda que sejam necessárias ferramentas analíticas adicionais para descobrir os motivos. Desse modo, é possível observar a combinação de "velhas" formas de contestação com novos elementos, algo fundamental para interpretar os períodos de ressurgimento do movimento estudantil depois de certo letargo. Mapearemos a seguir, de forma breve, os principais ciclos de ação coletiva dos movimentos estudantis no Brasil desde as lutas contra a ditadura até o

5 Trata-se de um recorte para definir uma periodização, mais que de um "marco inicial" dos movimentos estudantis no Brasil, que começaram a atuar já na década de 1930, ainda que bastante mais tarde que em outros países latino-americanos. Vide Marsiske (1989 e 1999). momento prévio de sua recente reapariçãos.

Em um primeiro momento, durante a década de 1960, as mobilizaçōes estudantis no Brasil foram conduzidas num campo político extremamente polarizado entre o Estado militar e a oposição estudantil. Entre a promoção do crescimento das forças produtivas a partir de uma "modernizaçáo conservadora" e o incremento da repressão, o 1968 estudantil brasileiro esteve 
marcado por importantes lutas, conectadas com outras lutas sociais, como as sindicais, e outras manifestaçôes culturais pós-I964, que seriam silenciadas de forma radical com o AI-5. A morte de Edson Luis no dia 28 de março, a greve geral do dia seguinte, a "Passeata dos Cem Mil" do dia 26 de junho ou a repressão ao Congresso da UNE, realizado em Ibiúna, foram os principais marcos de um ciclo de lutas que seria seguido por um período de clandestinidade e exílio, em que a repressão e o arbítrio seriam a tônica dominante. Durante esse período, surgiram vários estudos sobre os movimentos estudantis, porém uma referência obrigatória são os trabalhos de Foracchi (I965, I968), que realiza um aporte fundamental para o estudo da participação dos estudantes em movimentos políticos no País, ao avaliar as transformações da sociedade brasileira e o perfil dos estudantes, rompendo os enfoques com base em comportamentos e valores, para analisá-los como categoria social.

Somente em 1974, dez anos depois do golpe militar, e ainda no próprio regime, com as políticas de liberalização e de "distensão" de Geisel, reabre-se uma estrutura de oportunidades políticas mais favoráveis à rearticulação dos movimentos sociais, entre os quais os estudantis, que viveriam um segundo ciclo de açóes coletivas importantes. A partir de I975, a tensão contínua entre os militares e as forças democratizantes gerou uma dinâmica de "concessôes do regime e conquistas da sociedade", em uma conjuntura de resistência e luta democrática que, de forma contrária à década anterior, possibilitou a articulação de amplia plataforma de luta pelas liberdades democráticas (NASCIMENTO, 2007, p. 324). Entre os vários autores que analisaram esse período, Albuquerque (1977) lança uma importante contribuiçãa, aprofundando-se no tema da participação, por meio do caminho aberto por Foracchi e outros, indagando se o envolvimento no movimento estudantil contribui para a formação de uma consciência social duradoura. Combinando orientaçôes teóricas oriundas do funcionalismo e do acionalismo, o autor privilegia uma abordagem "touraniana" com base na noção de projeto, contribuindo muito para traçar os sentidos da ação 
coletiva (incluindo também seus pressupostos). Para isso, Albuquerque considera o movimento estudantil como movimento social, e a participação estudantil, como resultado da elaboração de um projeto pessoal, no sentido de Touraine.

Em um terceiro momento, já na década de 1980, em um período de reconstrução institucional, viriam ainda o "Movimento pela Anistia" e as "Diretas Já". Apesar de a atividade da sociedade civil permanecer forte, o cenário que emergia com o governo civil de Sarney até o impeachment de Collor de Mello estaria mais baseado na negociação que no conflito, em razão da saída formal dos militares do governo. Nesse período, as campanhas pela participação popular na Assembleia Constituinte teriam grande impacto, mas também serviriam para anunciar as dinâmicas futuras das lutas estudantis no País. De acordo com o estudo de Michiles (1989) sobre as emendas populares e a participação de organizaçóes e movimentos sociais, os estudantes apresentaram cinco emendas, mas somente uma conseguiu mais de cem mil assinaturas. Isso poderia levar a uma dupla interpretação: o refluxo, em termos de impacto político, das lutas estudantis e uma institucionalização da ação coletiva estudantil que passava a gravitar em torno de entidades estudantis pré-constituídas, principalmente a Uniāo Nacional dos Estudantes (UNE), as Unióes Estaduais de Estudantes (UEEs) e os Diretórios Centrais de Estudantes (DCEs).

Nesse sentido, na década de I990, deve-se considerar, em um contexto mais amplo, a mudança nos marcos de ação coletiva dos movimentos sociais brasileiros e latino-americanos, a aplicação de políticas neoliberais e a abertura a um processo de globalizaçáo que passa a considerar a educaçáo como palavra-chave nos discursos de governos, atores privados e de instituiçóes multilaterais como o Banco Mundial que fazem recomendaçóes para a flexibilização e redução de gastos, incidindo nos rumos das reformas educativas (vide GOHN, 2005). Além disso, a universidade passa por um incessante processo de transformação, proliferando as instituiçóes particulares "vende- 
doras de diploma", a valorização do quantitativo, a tecnificação da atividade intelectual e uma perda da produção e do ambiente de formação crítica. Essas não são questốes secundárias para pensar sobre a desmobilização estudantil na década de 1990, em que os estudantes estiveram marcados pela apatia, limitados, em geral, a demandas internas e ao reporte de algumas questóes por meio dos Diretórios Centrais dos Estudantes (DCEs) e demais "instituições estudantis". Vários autores, como Mische (1997, 2008) e Barbosa (2002), chegam a considerar a aparição dos "caras-pintadas" durante o processo de impeachment de Collor como a única manifestação juvenil que rompe com a apatia e o individualismo da geração shopping center. Esse poderia ser considerado um quarto ciclo de açáo coletiva das lutas estudantis, ainda que devamos lembrar que os "caras-pintadas" foram atores de uma mobilização mais ampla da sociedade civil.

\section{O movimento estudantil volta à cena em 2007 e 2008}

\section{I Convergências com outros movimentos sociais contemporâneos}

Depois da longa apatia da década de 1990, as ocupaçôes de reitorias durante os anos 2007 e 2008 aparecem como a "nova cara visível" dos movimentos estudantis brasileiros. Além do caráter novedoso dos marcos de ação coletiva utilizados pelos estudantes, o recente ciclo de mobilização estudantil supõe um novo ponto de inflexão nas lutas estudantis brasileiras também no que se refere ao questionamento das dinâmicas organizativas e mobilizatórias das últimas duas décadas, a partir de uma maior horizontalidade da informação, da deliberação e da ausência de lideranças definidas. Em suma, ante a centralização, hierarquização e partidarização das lutas estudantis (expressadas, nas últimas duas décadas, pelo controle político dessas lutas pelos centros 
e diretórios de estudantes, a maioria cooptados por partidos políticos) aparece um formato mais "movimentista", no qual primam:

- Maior democratização da informação e da comunicação: os blogs foram utilizados pela primeira vez nas açóes coletivas estudantis, durante as ocupações das reitorias, servindo não somente de ferramenta mais aberta e direta de comunicação, em razão de seu caráter mais interativo, mas também de via para a formação (como base para debates e "arquivo" de textos e documentos relevantes) e para a mobilização (referente para divulgar açóes futuras e linhas a seguir);

- Maior horizontalidade na deliberação: maior protagonismo das assembleias em detrimento dos comitês fechados e órgãos de representação;

- Ausência de um líder definido: não há um líder responsável ou um porta-voz único nas recentes ocupaçóes das reitorias, mas, sim, uma liderança difusa. Os estudantes alternavam-se nessa função. A falta de um interlocutor definido causou certo espanto nos poderes e meios mais tradicionais, por não poderem apontar um responsável concreto ou encontrar uma figura-líder com quem negociar;

- Certo grau de imprevisibilidade: a ausência de uma organização centralizada e institucionalizada para decidir o teor dos debates, as ações coletivas a ser realizadas etc. permitiu uma maior abertura nas tomadas de decisão relevantes e na definição das agendas.

$6 \mathrm{Um}$ excelente estudo recente que trata dessa retroalimentação entre a participação dos jovens em movimentos sociais contemporâneos, como o antiglobalização, e as novas práticas dos movimentos estudantis no Brasil é a tese de doutoramento de Marcos Ribeiro Mesquita (2006). Para uma análise das características do movimento antiglobalização, vide Echart, López e Orozco (2005).
Essas características dos movimentos estudantis brasileiros recentes, ao mesmo tempo que chocam com as dinâmicas prévias das lutas estudantis, aproximam-nos das lutas de outros movimentos sociais, como os de antiglobalização, e outros latino-americanos, que emergem no século XXI. Isso nos leva a sugerir que os movimentos estudantis respondem a uma dinâmica cíclica, com certo grau de retroalimentação decorrente da atuação dos demais movimentos sociais ${ }^{6}$. Os zapatistas mexicanos seriam os primeiros a apropriar-se 
das novas tecnologias como ferramenta de mobilização e difusão, propagando essa prática entre os movimentos sociais que desde I999, com os protestos contra a OMC, em Seattle, continuam aperfeiçoando seu uso. A horizontalidade na deliberação e a ausência de um líder definido também são características da maioria dos movimentos sociais latino-americanos que surgem nos últimos anos, desde os piqueteiros argentinos até os cocaleiros bolivianos, compartilhando, assim, um marco mais amplo de desconfiança dos jovens e do resto da população ante as instituiçóes, os partidos políticos e os políticos profissionais, e das dinâmicas organizativas dos próprios movimentos sociais. No caso das recentes mobilizaçóes estudantis no Brasil, apesar dessa tendência, várias foram as acusaçóes - sobretudo dos meios de comunicação hegemônicos e de intelectuais que parecem não estar sintonizados com outras formas de fazer política - contra o aparelhamento do movimento estudantil. Como resposta, em várias ocupaçóes como a da USP, os estudantes optaram por publicar uma carta aberta, argumentando a favor da autonomia do movimento em relação aos partidos políticos e sindicatos7. Daí a importância de uma reinterpretação das formas de militância da juventude no contexto atual (ver GROPPO; FILHO; MACHADO, 2008). O Movimento Hip-Hop, do passe-livre, entre muitos outros, deve ser considerado na formação política e socializaçáo dos jovens, influenciando a nova militância dos movimentos estudantis contemporâneos.

Sem incorrer no erro de mistificar as práticas e açóes coletivas recentes dos movimentos estudantis brasileiros e abusar da criação de atores, sociedades e futuros ${ }^{8}$ (algo caro às geraçóes dos anos I950, I960 e I970 e que deve ser aprendido), essas ocupaçóes, manifestaçóes, greves e dinâmicas organizativas apontaram para certa radicalização ideológica, num espectro mais afim aos demais movimentos sociais brasileiros do que aos partidos políticos de centroesquerda, como vinha sendo habitual. De fato, o recurso à ocupação como ação coletiva estratégica é outro rasgo convergente com os movimentos sociais contemporâneos, pois se trata de ação muito difundida entre os movimentos
7 Uma das várias ações simbólicas realizadas em algumas das ocupaçóes, e que denotava essa preocupação em reafirmar o caráter autônomo do movimento, foi realizar uma "lista de chamada" dentro das ocupaçôes: eram chamados vários nomes de estudantes participantes das ocupaçóes; de vez em quando, o responsável pela chamada lia o nome de algum dos partidos de esquerda, historicamente ligados ao movimento estudantil, e a resposta vinha em tom alto e uníssono: "ausente". Ilustrações à parte, é importante dizer que essa tendência movimentista não excluiu a participação de membros de partidos de esquerda, desde que não estivessem "representando" o partido, mas, sim, presentes a título individual.

8 Isto não significa negligenciar a importância de recuperar a memória política dessas lutas, e sim pensar os sentidos sobre o passado que circulam socialmente, assim como, por exemplo, as ressignificaçốes que os diferentes contextos e geraçóes encontram num mesmo episódio (JELIN, 2002). Um interessante artigo sobre os diferentes significados que as geraçóes posteriores de estudantes atribuíram à figura de Edson Luis pode ser encontrado em Langland (2006). 
sociais brasileiros, sejam urbanos ou rurais, e cujo caso mais paradigmático talvez continuem sendo os acampamentos do MST. Contudo, em termos de alcance, trata-se de uma radicalizaçáo ideológica que dista bastante daquela da década de 1960, náo estando vinculada à luta contra a autoridade e pela liberdade, tendo como objetivo central a mudança da sociedade, mas, sim a um foco centrado na mudança do funcionamento e função da universidade.

\subsection{Breve cartografia das lutas estudantis recentes}

Os números são significativos: durante os anos 2007 e 2008 , pelo menos 30 universidades públicas de todas as regiōes do País assistiram à ocupaçáo de suas respectivas reitorias pelos estudantes e/ou a protestos e

9 Houve ocupaçôes de reitorias e outras açōes coletivas como manifestações, greves e paralisaçóes em universidades do Rio Grande do Sul, Santa Catarina, Paraná, São Paulo, Rio de Janeiro, Minas Gerais, Espírito Santo, Bahia, Alagoas, Pernambuco, Ceará, Maranhão, Pará, Rondônia, Mato Grosso e Goiás. Para uma análise mais detalhada das reitorias ocupadas e protestos, vide Bringel (2008). das reitorias como principal forma de contestar as políticas vigentes, as reformas por vir, as gestôes nefastas de muitas universidades, e de explicitar as demandas dos estudantes e o conflito, dá um lugar de destaque - e de certa forma novedoso - a essa açáo coletiva no seio do movimento estudantil brasileiro. Deslocam-se assim, ainda que sem substituí-las, as greves como ação coletiva "clássica" das lutas estudantis brasileiras. Em alguns casos, como na longa paralisaçáo de 86 dias, em 2007, na Universidade Federal de Sergipe (UFS), a greve continuou sendo o recurso mais utilizado, porém a tendência geral foi uma coexistência das duas estratégias. Por outro lado, é importante destacar que a irradiação dessas ações coletivas não respondeu exclusivamente à convocatória de associaçóes, centrais ou comitês de estudantes previamente constituídos, mas, conforme destacado, se deve a um processo em que primaram a conformaçáo de novas assembleias mais horizontais e a ausência de uma liderança estudantil marcada, dando lugar inclusive para o questionamento à hierarquização, à burocratização e à centralização da organizaçáo estudantil no Brasil. 
O primeiro caso de ocupação de uma reitoria pelo movimento estudantil, durante 2007, deu-se em março na Universidade Estadual de Campinas (Unicamp). Naquele momento, a reivindicação estava vinculada a uma demanda interna (reforma, melhora e ampliação da residência universitária, em Barão Geraldo). Ainda no âmbito da moradia, a Universidade de Brasília (UnB) viveu um episódio violento, quando, no fim de março, a ala da Casa do Estudante Universitário onde residiam estudantes africanos foi incendiada, em um ato que aponta a indícios racistas. Contudo, a ocupação que repercutiria com maior intensidade no período inicial de fluxo das ocupaçóes foi a da USP, em razão de sua larga duração, do porte da universidade, da midiatização do processo e da estruturação e organização da ocupação. No dia 3 de maio de 2007 , após assembleia, alunos da USP dirigiram-se ao prédio da reitoria para entregar uma carta com reivindicaçôes à reitora Suely Vilela. Diante da ausência da reitora (e de diálogo), os estudantes decidiram ocupar a reitoria. Os decretos do governador José Serra que, de acordo com os estudantes, feriam a autonomia universitária seriam responsáveis por acentuar o conflito, sendo alvo de várias mobilizações, greves (não só de alunos, mas também de servidores e professores, como as iniciadas no dia 23 de maio na USP e em algumas faculdades da Unicamp) e também desencadeariam a ocupação de outras reitorias no Estado de São Paulo, tais como a Universidade Estadual Paulista (Unesp) e a Universidade Federal de São Carlos (UFSCar).

A esses "ataques" locais e regionais às universidades públicas somarse-ia, posteriormente, um fato de dimensão nacional que seria o catalisador de mobilizaçóes em todo o País: o lançamento, em 24 de abril de 2007, do Plano de Desenvolvimento da Educação (PDE), que contém cerca de quatro dezenas de medidas, entre as quais o Decreto n. 6.096 que institui o Programa de Apoio a Planos de Reestruturação e Expansão das Universidades Federais $(\mathrm{REUNI})^{\mathrm{Io}}$, que, mesmo sendo uma medida federal, foi definida como de adesão voluntária de cada Instituição Federal de Ensino Superior (IFES), por
Io Em agosto de 2007, o Grupo Assessor nomeado pela Portaria n. 552 SESU/MEC, de 25 de junho de 2007, apresentou o documento de Diretrizes Gerais do REUNI, que define os parâmetros de cálculo das metas globais e dá orientação para a elaboração dos projetos. 
decisão do respectivo Conselho Universitário. Daí a pressão "local” dos estudantes nos conselhos de suas próprias universidades.

A reitoria da USP seria desocupada no dia 22 de junho, mas muitas outras reitorias seguiriam ocupadas pelos movimentos estudantis, que utilizariam como bandeira comum de luta a defesa da universidade pública de qualidade. A crítica ao REUNI foi o principal eixo articulador das demandas, recebendo, de modo geral, as seguintes críticas: escassez ou ausência de diálogo no processo de elaboração (caráter antidemocrático); atentado contra a autonomia universitária (a eventual liberação de recursos estaria condicionada ao atendimento das diretrizes e metas estabelecidas pelo REUNI); ataque contra a democracia interna das instituiçôes (exigência de novas estratégias e cronogramas) e seu caráter público (expansão das possibilidades de introdução do setor privado, especialmente o de cunho mais mercantil, com possíveis reflexos inclusive nas linhas de pesquisa); preocupação com números e metas, e não com a qualidade do ensino; ampliaçáo do acesso à universidade sem o correspondente aumento dos investimentos feitos pelo Estado; REUNI como forma encontrada pelo MEC de viabilizar o projeto de "Universidade Nova" (este argumento foi muito utilizado na ocupação da UFBA, pois o dito projeto foi arquitetado por Naomar Almeida Filho, reitor dessa instituição).

No entanto, apesar de o REUNI ter sido o fio condutor que conectava as diferentes ocupaçóes, as distintas realidades regionais e locais também marcavam sua própria agenda: por exemplo, no Maranhão, o movimento estudantil assumiu também a luta contra a privatização dos espaços internos da universidade; em Santa Catarina, a aliança tática do movimento estudantil com outros movimentos sociais para determinadas açóes deram lugar a açóes conjuntas na Universidade Federal de Santa Catarina (UFSC); em várias universidades, a luta pelo passe livre viu-se fortalecida pelas ocupaçóes das reitorias, havendo numerosas manifestaçóes em todo o Brasil no dia 26 de outubro; na Universidade Federal do Pernambuco (UFPE), houve um conflito dentro do movimento estudantil entre aqueles que apoiavam a ocupaçáo e cri- 
ticavam o REUNI e o próprio DCE que defendia o plano de reestruturação do governo Lula, entre muitas outras particularidades dos conflitos no âmbito local. Em um momento posterior, já no ano 2008, as denúncias de corrupção e malversação de fundos públicos levaram a mais mobilizaçôes dos estudantes, que acabaram com a destituição de dois reitores, na UnB e na Unifesp. De certa forma, poder-se-ia dizer que a irradiação das açóes coletivas estudantis, durante os anos de 2007 e 2008 , contestou tanto as políticas educativas, interpelando as autoridades universitárias e governamentais, em um sentido exógeno, quanto as dinâmicas internas e formas organizativas e de mobilização existentes para "defender os interesses dos estudantes". Os estudantes participantes dessas mobilizações, muitos deles sem histórico militante prévio, tomaram a política pelas próprias mãos, negando a intervenção de representantes estudantis. Apesar da redundância e da ênfase, talvez exageradas, dessas práticas de contestação, "o movimento" se transforma novamente em "movimentos", com uma grande heterogeneidade e formas de fazer política.

\section{6 (Sem) Conclusão final}

Como brevíssima nota final, destaca-se que não é possível chegar a conclusões sobre se essas novas dinâmicas internas e externas dos movimentos estudantis brasileiros supóem uma verdadeira mudança que se prolongará no tempo. Provavelmente, não. As rupturas mencionadas são tendências que respondem a um processo de geometria variável, aberto e contraditório, motivo pelo qual não são permanentes, podendo haver aprofundamentos ou retrocessos, pois, como afirma Martins Filho, é impossível conferir ao movimento estudantil um caráter invariável e imutável (1987, p. 3I). Nesse sentido, ao tratar-se de "tendências", deve-se interpretá-las como uma propensão ou inclinação que se orienta em determinada direção, sendo imprescindível considerar os pontos de tensóes existentes, que podem encaminhar essa evolução em 
um ou outro objetivo. As dinâmicas cíclicas das ações coletivas estudantis, em consonância com as lutas de outros movimentos sociais, serão as responsáveis por imprimir maior sentido de longo prazo para o caráter atual da contestação estudantil que, no curto prazo, pelo menos, dá lucidez a um contexto de hegemonia da educação superior como negócio, de metamorfoses das universidades e de transição do pensamento crítico.

\section{The EARLIER FUTURE: CONTINUITIES AND RUPTURES IN BRAZILIAN STUDENT MOVEMENTS}

During 2008, the reflections on the struggles of students multiplied around the world due to the $40^{\text {th }}$ birthday of may I968. In Brazil, the most paradigmatic issue was not so much the discussion of the I96os struggles, but its "updating" of the current national context, based on the ruptures that recent protests of Brazilian students, with many actions and occupations between 2007 and 2008, may provoke in the scenario of student movements. A central hypothesis proposed in this paper is that these movements are manifested in accordance with cyclical dynamics and through feedbacks with other social movements. To observe this dynamics of continuity and breaks, some elements for a theoretical and methodological approach are proposed, which allows us to interpret student movements as a sui generis social movement. It is also performed a cyclical analysis of student collective actions in Brazil, and in historical perspective and compared with the dynamics of other social movements, the main features of the contemporary struggles of student movements in the country are evaluated.

KeY wORDs: Occupations. Protests. Social movements. Students. University. 


\section{Referências}

ALBUQUERQUE, J. G. Movimento estudantil e consciência social na América Latina. Rio de Janeiro: Paz e Terra, I977.

ARANDA, J. El movimiento estudiantil y la teoría de los movimientos sociales. Convergencia, ano 7, n. 2I, Toluca, México, 2000, p. 225-250.

BARBOSA, A. A (des)articulação do Movimento Estudantil (décadas de 80 e 90). Educação: teoria e prática, v.10, n.18/19, p.5-I4, 2002.

BRINGEL, B. Ação coletiva e autonomia no movimento estudantil brasileiro: rupturas e sentidos das ocupaçóes das reitorias em 2007. In: CONFERENCIA INTERNACIONAL EDUCACAO, GLOBALIZACAO E CIDADANIA. Research Committee on Sociology of Education, Associação Internacional de Sociologia, João Pessoa, fev. 2008. .; ECHART, E. Movimentos sociais e democracia: os dois lados das 'fronteiras'. Caderno CRH, Salvador, v. 2I, n. 54, p. 457-475, set./dez. 2008.

BRITO, S. (Org.). Sociologia da juventude. Da Europa de Marx à América Latina de hoje. v. I. São Paulo: Zahar, i968.

COLECTIVO MALDEOJO. Estudiantes, antiestudiantes, policía, prensa y poder. Madrid: Traficantes de Sueños / Literatura Gris / Colectivo Maldeojo, 200I.

DERRIDA, J. De la grammatologie. Paris: Editions de Minuit, 1967.

ECHART, E.; LÓPEZ, S.; OROZCO, K. Origenes, protestas y propuestas del movimiento antiglobalización. Madrid: IUDC/Catarata, 2005.

FERNANDES, F. Universidade brasileira: reforma ou revolução? São Paulo: Alfa-Ômega, I979.

FEUER, L. The conflict of generations. The character and significance of students movements. Nova York/Londres: Basic Books Publishers, 1969.

FORACCHI, M. O estudante e a transformação da sociedade brasileira. São Paulo: Companhia Editora Nacional, 1965.

. Estudiante y política en Brasil. In: SOLARI, Aldo (Org.). Estudiantes y politica en América Latina. Caracas: Monte Ávila Editores, 1968. p.433-457. 
GOHN, M.G. Movimentos sociais e educação. 6. ed. São Paulo: Cortez, 2005.

Teorias dos movimentos sociais. Paradigmas clássicos e contemporâneos. 5. ed. São Paulo: Loyola, 2006.

GROPPO, L. A.; FILHO, M. Z.; MACHADO, O. L. (Org.). Movimentos estudantis na contemporaneidade. Recife: Editora da UFPE, 2008.

IANNI, O. O jovem radical. In: BRITO, S. (Org.). Sociologia da juventude. v. I: Da Europa de Marx à América Latina de hoje. Rio de Janeiro: Zahar Editores, I968. p.225242.

IBARRA, P.; BERGANTIÑOS, N. Movimientos estudiantiles: de mayo del 68 a la actualidad. Sobre las experiencias 'utópicas' de un movimiento peculiar. In: ASAMBLEA DE CIENCIAS SOCIALES POR UNA UNIVERSIDAD CRÍTICA. Movimientos estudiantiles: resistir, imaginar, crear la universidad. Donosita/San Sebastián: GAKOA, 2008, p.II-27.

JELIN, E. Los trabajos de la memoria. Buenos Aires: Siglo XXI, 2002.

LANGLAND, V. 'Neste luto começa a luta': la muerte de estudiantes y la memoria. In: JELIN, Elizabeth.; SEMPOL, D. (Comps.) El pasado en el futuro: los movimientos juveniles. Buenos Aires: Siglo XXI, 2006. p. 2I-64.

LARAÑA, E. "Continuidad y unidades en las nuevas formas de acción colectiva. Un análisis comparado de movimientos estudiantiles”. In: LARAÑA, E.; GUSFIELD, J. (Eds.) Los nuevos movimientos sociales. De la ideología a la identidad. Madri: Centro de Investigaciones Sociológicas-CIS, 1994, p.253-285.

MARINI, R. M. Les mouvements étudiants en Amérique Latine. Les temps modernes, $\mathrm{n}$. 29I, out. Paris, 1970.

MARSISKE, R. (Coord.). Movimientos estudiantiles en la historia de América Latina. v. 2. México D.F.: UNAM, I999.

Movimientos estudiantiles en América Latina: Argentina, Perú, Cuba y México: I9I8-I924. México D.F.: Siglo XXI, I989.

MARTINS FILHO, J. R. Movimento estudantil e ditadura militar: 1964-1968. Campinas: Papirus, 1987.

MENDES, A. Movimento estudantil no Brasil. São Paulo: Brasiliense, I98I. 
MESQUITA, M. Identidade, cultura e politica: os movimentos estudantis na contemporaneidade. Tese (Doutorado em Psicologia Social)-PUC-SP, São Paulo, 2006.

MICHILES, C. et al. Cidadão constituinte: a saga das emendas populares. Rio de Janeiro: Paz e Terra, 1989 .

MISCHE, A. De estudantes a cidadãos. Redes de jovens e participação política. Revista Brasileira de Educação, n. 5, maio/ago., 1997, p.134-150.

. Partisan publics: communication and contention across Brazilian youth activist networks. Princeton: Princeton University Press, 2008.

NASCIMENTO, M. P. Lutas democráticas contra a ditadura. In: FERREIRA, J.; AARÃO REIS, D. (Org.). Revolução e democracia (1964 -...). Rio de Janeiro: Civilização Brasileira, 2007. p. $32 \mathrm{I}-353$.

NEUVEU, E. Sociologie des mouvements sociaux. Paris: La Découverte \& Syros, I996.

RIBEIRO, D. A universidade necessária. Rio de Janeiro: Paz e Terra, I969.

SÁENZ, A. M. Notas para un análisis bibliográfico del movimiento estudiantil mexicano de 1968. In: CONGRESO INTERNACIONAL DE AHILA, I5, Leiden, Holanda, agosto de 2008 .

TARROW, S. Struggle, politics and reform: collective action, social movements and cycles of protest. Western Societies Program, Occasional Paper, n.21, 2 ed., Center for International Studies. Ithaca: Cornell University, I99I.

. Power in Movement: Social Movements, Collective Action and Politics.

Cambridge: Cambridge University Press, 1998.

TILLY, C. From mobilization to revolution. Nueva York: McGraw-Hill, 1978.

Sage, 1984 .

. Big Structures, Large Processes, Huge Comparisons. Nueva York: Russel

Recebido em I3 abr. 2009 / aprovado em I3 maio 2009.

Para referenciar este texto

BRINGEL, B. O futuro anterior: continuidades e rupturas nos movimentos estudantis do Brasil. EccoS, São Paulo, v. II, n. I, p. 97-I2I, jan./jun. 2009. 
